\title{
Skilled Nursing Facility
}

National Cancer Institute

\section{Source}

National Cancer Institute. Skilled Nursing Facility. NCI Thesaurus. Code C154428.

An in-patient medical facility equipped with a trained nursing staff that provides a wide range of health and personal care services, with a focus on medical care. These services typically include nursing care, 24-hour supervision, three meals a day, and assistance with everyday activities. 